\title{
Artisanal and Small-Scale Mining Sites in the Democratic Republic of the Congo Are Not Associated with Nighttime Light Emissions
}

\author{
Christopher C. M. Kyba ${ }^{1,2, * \mathbb{C}}$, Grégory Giuliani ${ }^{3,4}{ }^{(0)}$, Florian Franziskakis ${ }^{3,4}$, Klement Tockner 5 \\ and Pierre Lacroix ${ }^{3,4}$ (D) \\ GFZ German Research Centre for Geosciences, Telegrafenberg, 14473 Potsdam, Germany \\ Leibniz-Institute of Freshwater Ecology and Inland Fisheries, Müggelseedamm 310, 12587 Berlin, Germany \\ Institute for Environmental Sciences, University of Geneva, GRID-Geneva, Bd Carl-Vogt 66, \\ CH-1211 Geneva, Switzerland; gregory.giuliani@unige.ch (G.G.); Florian.Franziskakis@etu.unige.ch (F.F.); \\ Pierre.Lacroix@unige.ch (P.L.) \\ 4 Institute for Environmental Sciences, University of Geneva, EnviroSPACE Lab, Bd Carl-Vogt 66, \\ CH-1211 Geneva, Switzerland \\ 5 FWF Austrian Science Fund, Sensengasse 1, 1090 Vienna, Austria; Klement.Tockner@fwf.ac.at \\ * Correspondence: kyba@gfz-potsdam.de; Tel.: +49-30-2882-8973
}

Received: 28 March 2019; Accepted: 16 April 2019; Published: 20 April 2019

\begin{abstract}
Maintaining records of artisanal and small-scale mining sites in developing countries requires considerable effort, so it would be beneficial if Earth observation data from space could assist in the identifying and monitoring of such sites. Artificial light emissions are common at industrial-scale mining sites and have been associated with small-scale illegal mining in some contexts. Here, we examine whether known artisanal and small-scale mining sites in the Democratic Republic of the Congo (DRC) are associated with observations of night light emissions by the Visible Infrared Imaging Radiometer Suite Day/Night Band (DNB). Light emissions from the mining sites were not observed: the radiance observed from the sites was near zero and nearly identical to that observed for a set of randomly-chosen locations in the same region. While it is the case that DNB night lights' products provide useful data in other resource extraction contexts, they do not appear to be useful for identifying artisanal mining sites in the DRC.
\end{abstract}

Keywords: artisanal mining; Democratic Republic of the Congo; night lights; remote sensing; VIIRS DNB

\section{Introduction}

Artificial light emissions provide a clear indication of human activity at night [1]. Hence, the detection of such lights may help to identify or monitor certain activities, for example fishing [2] or gas flaring associated with energy resource extraction [3,4]. Therefore, night lights can potentially assist in the identification of related illegal activities, including but not limited to fishing [5,6] or mining [7]. At the same time, night lights can also be used to evaluate the effectiveness of government measures to limit such activities [7].

This study examines whether night lights' data could be used to support the identification and monitoring of small-scale mining operations, by comparing observations of night lights to known mining locations in the Democratic Republic of the Congo (DRC; readers may find the list of abbreviations prior to the bibliography useful). Maintaining records of mining sites is a challenge in the DRC due to insecurity, natural conditions, unauthorized access, and to the fact that mine sites can move with time. The ability to measure site activity through Earth Observation (EO) tools, such as satellite 
imagery, would better support environmental impact assessment of mining activities. Moreover, it could help with raising awareness of the health consequences of bad practices in mineral extraction among artisanal miners and local populations. Finally, improved records could also potentially reduce local conflicts and improve dialogues between the various stakeholders of the extractive sector in the DRC.

\section{Background: Artisanal Mining in the DRC}

\subsection{Issues and Challenges Related to the Artisanal and Small-Scale Mining Sector}

The Democratic Republic of the Congo (Central Africa) exhibits enormous mineral potential, especially for gold and 3T minerals (cassiterite, wolframite, and coltan, respectively mined for Tin, Tungsten, and Tantalum). The country's untapped minerals are estimated to be worth 24 trillion USD [8], yet given the insecurity coupled with corruption, the vast majority of society does not seem to profit from this natural wealth, making DRC a good example of the "resource curse" [9-11].

Artisanal and Small-scale Mining (ASM) comprise the backbone for DRC economic development and a source of employment for millions of people [12]. The constant rising of the global mineral demand over the last decades and the lack of state regulation make ASM a profitable sector. Indeed, between 80 and $90 \%$ of the total production and exportation of minerals from DRC (especially eastern DRC) is estimated to originate from informal mining sites [10,12].

One of the current challenges is integrating economic activity with effective governance systems, environmental integrity, and social concern [13,14]. Abandoned mines and artisanal and active mining activities generate large amounts of liquid and solid hazardous waste and are considered as major sources of increased pollution with subsequent impacts on both human and environment health in many regions of the DRC, and beyond.

This situation does not allow authorities to ensure proper disposal of toxic and hazardous wastes harmful to humans and the environment. Therefore, activities linked to ASM in the DRC are expected to continue causing serious human and environmental health impacts, as well as social conflicts. The environmental and negative social impacts of the mining sector are a major obstacle to building trust and moving forward in economic growth, and toward a sustainable future.

\subsubsection{Lack of Formal State Control}

Struggling with wars (1996-1997 and 1998-2003), political instability, and corruption, the DRC has been propitious for illegal and unregulated activities in ASM, especially in the eastern part of the country. The small scale and relative mobility of the mining sites make it difficult for the state to have actual control over the activity.

In this frame, the International Peace Information Service (IPIS) compiled already existing data and carried out several field campaigns in eastern DRC to visit and collect data on artisanal mining sites ([15]). More than 2400 sites were visited, providing a strong fact-based information source for stakeholders implicated in the region (Figure 1). A majority of sites was visited during the 2013-2015 period (1615 sites for almost 240,000 workers). 


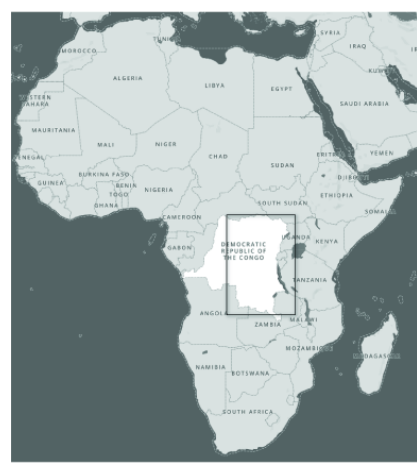

Main mined mineral

in each artisanal site

Gold

- Amethyst

- Cassiterite

- Copper

- Coltan

- Diamond

- Monazite

- Tantalite

- Tourmaline

- Wolframite

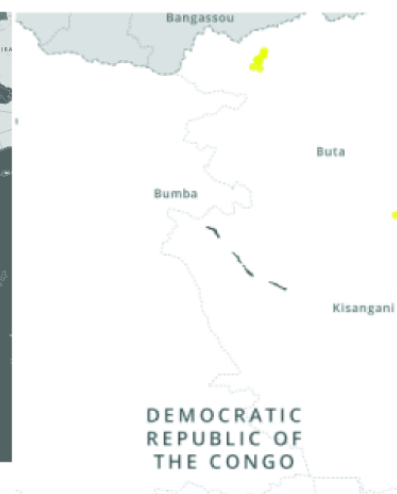

THE CONGO

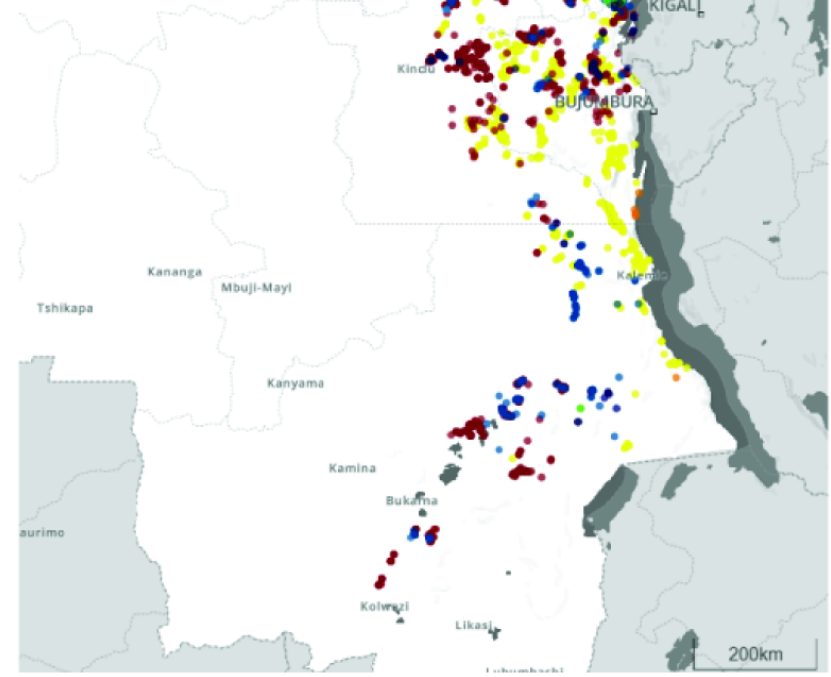

Figure 1. Artisanal mining sites of the DRC classified by minerals [16] (see also [15]).

According to [15], out of 2403 artisanal sites visited since 2009, 62\% of them are located on exploration or exploitation zones for industrial companies. Only 15 out of these sites are located on a "Zone d'exploitation artisanale" (artisanal exploration zone), where such activity is permitted according to the DRC law.

ASM is a sector of vital importance, but is largely part of an unregulated parallel economy and linked to conflict zones. In an attempt to address this issue, the former Congolese President Joseph Kabila declared a six-month ban on the export of artisanal mining products in both Kivu and Maniema Provinces between 2010 and 2011. Not only was this ban not respected, but it also enhanced the insecurity among the local human population [10].

Simultaneously, the U.S. Congress passed the Dodd-Frank Act, which contained a section requiring the companies on the U.S. stock market to trace the origin of 3T minerals and gold. This act aimed to ban their importation from conflict zones, but was eventually suspended by U.S. President Trump in 2017 [17].

\subsubsection{Presence of Armed Actors}

Taking advantage of the unregulated ASM sector and large profit opportunities, several armed actors seized control of mining sites in the region. These armed actors include official state forces (FARDC), as well as non-state forces. For the 2013-2015 period, the presence of at least one armed group was observed for $56 \%$ of the 1615 visited mining sites (see Figure 2). This armed control is more important for gold workers (64\%) than $3 \mathrm{~T}$ workers $(21 \%)$, not because of a lack of interest in these minerals, but rather because the $3 \mathrm{~T}$ mining sites are located in more demilitarized regions in the southeastern part of the country (Katanga, Bisie Mpama; see Figure 2). 


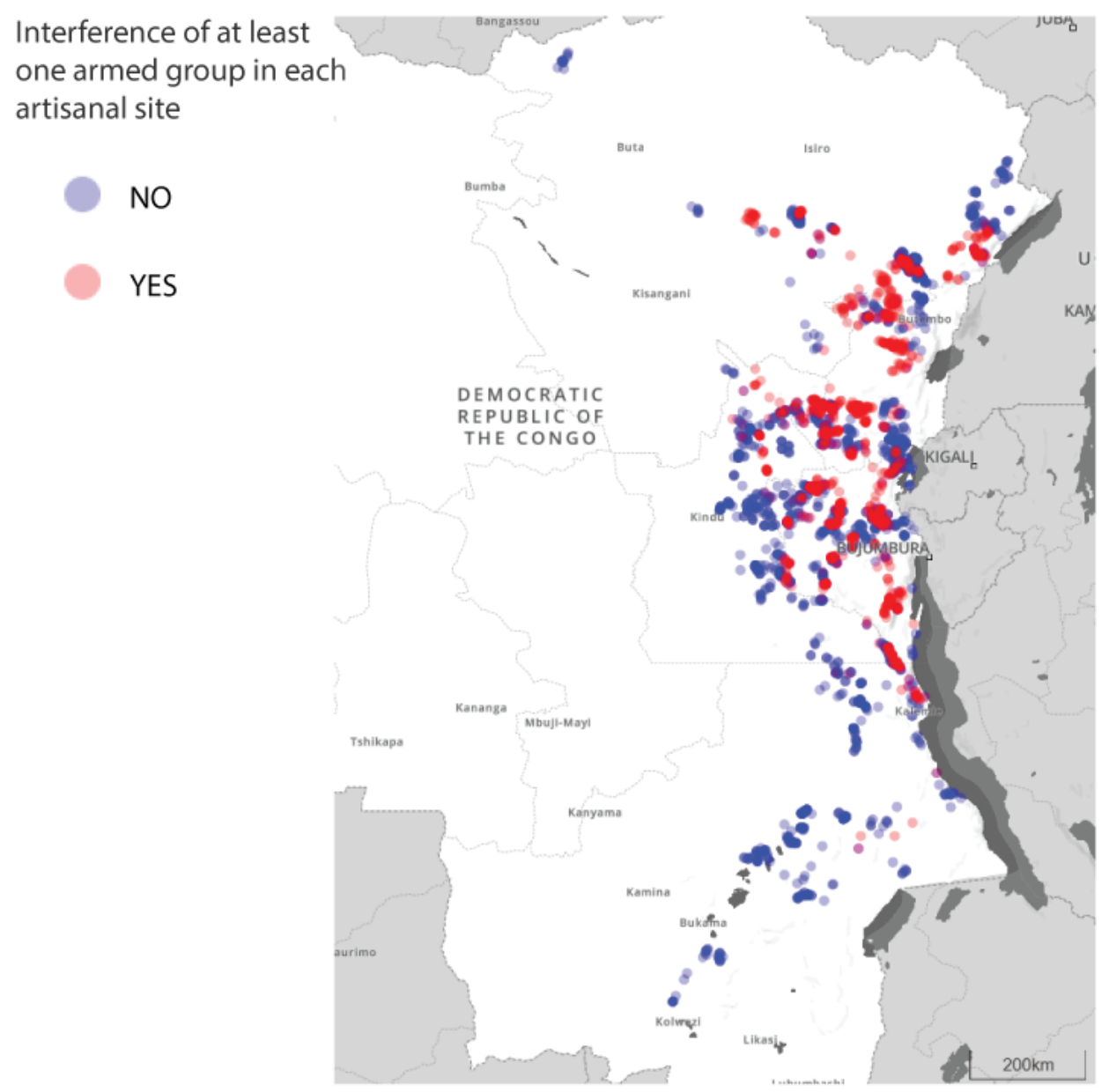

Figure 2. Armed group(s) interference with mining activities in the DRC [16] (see also [15]).

\subsubsection{Environmental Issues}

Apart from degrading the landscape by unregulated exploitation, artisanal mining is often associated with the use of mercury for gold recovery via the amalgamation process. This technique has the advantage of being relatively simple, efficient, and inexpensive $[18,19]$, but is now widely recognized as a major source of environmental pollution. The spilling of mercury into the environment and its biomagnification through the food chain can cause great damage to the local human population. Exposure to mercury is the cause of many human diseases [20] and has been globally exposed to the public after the Minamata Convention on Mercury was signed in 2013.

The use of mercury for gold recovery in eastern DRC artisanal mines has only been recorded by field teams since 2015; therefore, all previous campaigns do not have data on the subject. Out of the 793 concerned mining sites, 120 of them record the use of mercury (about $15 \%$ of the total). Though this proportion seems quite low, it is estimated that 15 tons of mercury are used annually in ASM for gold recovery in the DRC [8].

\subsubsection{Social Issues}

The DRC is frequently described as a country that is a victim of the resource curse, with very limited growth and unstable political governance despite being rich in natural resources. Miners employed in ASM often work under rough conditions with the interference of armed actors [9]. The economic stakes linked to the exploitation of mineral resources tend to bring tensions and violence between the people working and the faction that controls the land [11,17].

The bans on minerals from conflict zones (2010-2011) did not have the expected positive impact, which was to lower the illegal activities of artisanal mining, but rather had negative consequences. After 
the ban, many unemployed miners turned to criminal activities as a new source of income. Violence against civilians and looting increased, as well as riots and protests against the government [17].

\subsection{Traditional Methods for Collecting Information on Artisanal Mining}

In order to compile spatially-explicit information about artisanal mining sites, field campaigns were organized by IPIS, Bundesanstalt für Geowissenschaften und Rohstoffe (BGR), and other associated institutions such as the Ministère des Mines of the DRC, the International Organization of Migration (IOM), and the World Bank's PROMINES. Data were collected in 12 provinces of eastern DRC between 2009 and 2017 (field campaign projects IPIS-2009, IPIS-2010, IPIS-PROMINES MoFA2013-2014, IPIS-IOM PROMINES 2015, IPIS-IOM 2016-2018, IPIS-PPA Mambassa 2017, iTSCi (ITRITin Supply Chain Initiative) status, and DRC State Qualification status). It would be a major boon if it were found that remotely-sensed data could support these efforts.

\section{Materials and Methods}

\subsection{Mine Data}

The mine dataset used in this research concerned artisanal mining activities (ASM) in eastern DRC. It was compiled and updated by IPIS and contained both spatial and non-spatial information about mining sites in the region for a total of 3687 listed entries [16]. The data may be visualized on the interactive map in Web Map Service (WMS) and is open for download on GeoServer in all traditional formats including Esri Shapefile, KML, and GeoJSON (http:/ /ipisresearch.be/home/conflict-mapping/maps/open-data/).

Data published by IPIS are available under the "Open Data Commons Attribution License (ODC-BY) v1.0" license and are updated on a regular basis, often following reports' release or after new field campaigns are done. One major asset of this dataset is that it is up-to-date ground-based information for researchers and people in the field. As of October 2018, the compiled data contained information about 2403 different mining sites. Some of these sites were visited during numerous campaigns; hence, the number of sites does not match the number of entries. Furthermore, due to the artisanal and small-scale character of these mines, it is possible that their exact location may change from year to year.

Information listed for each site can be grouped into four main categories, which are (1) general information, (2) mine features, (3) armed actors, and (4) state services:

1. General information is about the data source, the project from which they were collected, the name of the mining site, its location, and the closest village. It is also indicated if the site was indeed visited by the investigators or not, e.g., because of insecurity, natural or road conditions, or unauthorized access.

2. Mine features correspond to the number of workers, whether the site is mined for gold and/or 3T minerals, the main mineral of interest, along with the two other main minerals. For all listed minerals, their closest selling point and their final destination inside DRC are indicated. Finally, the use of mercury for the recovery of the gold is indicated, if it took place.

3. The presence/absence of armed actors at the mining site is indicated, and if present, whether or not they are conducting illegal activities (interferences). If the presence of one or more armed actors is observed, information is given for each one of them including its type: foreign or local group, state or non-state, the frequency of presence at the mining site, the type of interference such as taxation of the production, control of the passage, monopoly on the production, and buying of minerals, forced laboring of the workers, and pillaging of the site.

4. The presence/absence of state services at the mining site also indicate if each site is under the iTSCi watch and its status concerning child and female labor, as well as general working conditions. 
The degree of precision and completeness of this dataset and its derived maps (e.g., [16]) have the potential to support stakeholders of the extractive sector in carrying out fact-based decisions and taking proper action. ASM represents many livelihood opportunities for the local communities of eastern DRC, which impacts the underground economy, but also enhances violence and political instability across the entire country ([17]). The origin of the extracted minerals poses ethical questions for international companies that do not want to be associated with conflicts and violence. The derived maps are therefore a useful tool to better understand the magnitude and complexity of the problem. They are also user friendly and allow quick and clear visualization and filtering of the data, especially for users with limited GIS knowledge.

\subsection{Night Lights' Data and Analysis}

Night light emissions during the period April 2012-December 2017 were examined using data acquired by the Visible Infrared Imaging Radiometer Suite Day/Night Band (DNB) on the Suomi NPP satellite [21]. The intrinsic spatial resolution of DNB data is $\sim 750 \mathrm{~m}$ (pixel area of $\sim 0.56 \mathrm{~km}^{2}$ ) [22], but the data analyzed here were composited and reprojected onto a 15 arc-second grid by the National Oceanic and Atmospheric Administration (NOAA). The NOAA composites removed data with bright moonlight and cloud-covered scenes [23].

The DNB is extraordinarily sensitive, to the point that atmospheric airglow can be seen, reflected by clouds $[22,24,25]$. Lighting installations as small as about a dozen streetlights rise clearly above the background; representative values for observed radiance in $\mathrm{nW} /\left(\mathrm{cm}^{2} \cdot \mathrm{sr}\right)$ are given in Table 1 . Communities in the DRC are much less brightly lit than comparably-sized communities internationally. Mine sites in wealthy countries are frequently lit, and in the course of this study, we also observed several examples of illuminated areas at known industrial mine sites in the DRC. Readers are invited to examine aerial imagery and night lights' data for two selected sites using the Radiance Light Trends (RLT) web application [26] and Google Maps (GM):

- Industrial site RLT: https: / /ighttrends.lightpollutionmap.info /\#zoom=12\&lon=26.18226\&lat= $-10.57610$

- Industrial site GM: https://goo.gl/maps/44Sqa6Yauym

- ASM site RLT: https: / /lighttrends.lightpollutionmap.info /\#zoom=12\&lon=28.78363\&lat=-0.47599

- ASM site GM: https://goo.gl/maps/nniHKnqDxAP2

After opening the Radiance Light Trends link, readers should click the "layer options" at the top right, select aerial imagery as the base map, and then adjust the "lights layer opacity" to turn off the lights layer and reveal the aerial image below.

Radiance values vary from month to month in the composite datasets, and the stability of night lights data was recently discussed by Coesfeld et al. [27] and Ryan et al. [28]. For areas without electric light or light from biomass burning, the main sources of variation in the monthly composites can be attributed to changes in natural light (e.g., atmospheric airglow) and errors in the zero point calibration of the radiometer. Any analysis of dimly-lit sites must therefore account for changes in the reported radiance for areas with no artificial light. Our approach was to calculate the median DNB radiance for an ensemble of sites each month and compare each site's radiance to this "typical" value. 
Table 1. Typical radiance observed for selected sites in the DNB monthly composites. The population figures are rounded, based on values on Wikipedia. Further information about the typical values of different types of light sources was provided by Coesfeld et al. [27], and a case study of the brightest areas in megacities was provided in Kyba et al. [1].

\begin{tabular}{ccc}
\hline Light Source & Approximate Population & Typical Radiance $\left(\mathbf{n W} /\left(\mathbf{c m}^{2} \cdot \mathbf{s r}\right)\right)$ \\
\hline Greenhouses, oil flares & NA & $>1000$ \\
Midtown Manhattan, USA & 9 million & 350 \\
Heathrow Airport, U.K. & NA & 100 \\
Central Potsdam, Germany & 200 thousand & 40 \\
Central Kinshasa, DRC & 9 million & 35 \\
Ndjili International Airport, DRC & NA & 20 \\
Jänschwalde Mine, Germany (surface) & NA & 15 \\
Central Bukava, DRC & 10 million & 10 \\
Creighton Mine, Canada (underground) & NA & 8 \\
Tenke Mines (surface), DRC & NA & $1-50$ \\
Gülpe, Germany & 200 & 0.7 \\
Central Bumba, DRC & 100 thousand & 0.5 \\
Wilderness area, USA & NA & 0.15 \\
\hline
\end{tabular}

We assembled a set of quasi-random points in order to compare the radiance at ASM sites with sites that were unlit. An ensemble of comparison sites was created by randomly pairing latitudes and longitudes from the ensemble of ASM sites. The comparison sites were therefore drawn from a larger area than the ASM sites, including a few locations in neighboring countries in the east. A few of these sites may end up being located in areas with artificial light, but because of the small amount of artificial lighting in DRC, the vast majority will not.

For each monthly dataset, we calculated the difference $d$ between the observed radiance and the mean radiance for the ensemble (either ASM or comparison sites). For each site, we then found the 50th and 90th percentile difference ( $d_{50}$ and $d_{90}$ ) over the complete time series. If a site is unlit, then both $d_{50}$ and $d_{90}$ should be near zero, while if a site is regularly lit, with the equivalent light output of a few dozen streetlamps, then they should be above $1 \mathrm{nW} /\left(\mathrm{cm}^{2} \cdot \mathrm{sr}\right)$ (see Table 1$)$.

\section{Results}

Known artisanal mining sites in the Democratic Republic of the Congo are generally unlit. The median radiance of both the ASM and comparison ensembles were nearly identical in each month (Figure 3), implying that the typical ASM site is not lit. This was further demonstrated in the median and 90th percentile difference values $d$ (Figure 4). At both the ASM sites and the comparison sites, nearly all of the sites had both median and 90th percentile values well below $1 \mathrm{nW} /\left(\mathrm{cm}^{2} \cdot \mathrm{sr}\right)$ (cf. Table 1). This implies that not only are the sites not typically lit, they are very rarely, if ever, illuminated. The jump in mean radiance values around the start of 2017 can be attributed to a change in the calibration related to airglow subtraction [25].

Deviations from near zero light emissions were observed only for a small number of sites. One ASM site had a 90th percentile difference of $1.05 \mathrm{nW} /\left(\mathrm{cm}^{2} \cdot \mathrm{sr}\right)$, but its median value was only $0.14 \mathrm{nW} /\left(\mathrm{cm}^{2} \cdot \mathrm{sr}\right)$. Four comparison sites had a 90th percentile difference above $1 \mathrm{nW} /\left(\mathrm{cm}^{2} \cdot \mathrm{sr}\right)$; all four of these sites were associated with settlements (verified using Google Earth imagery). 


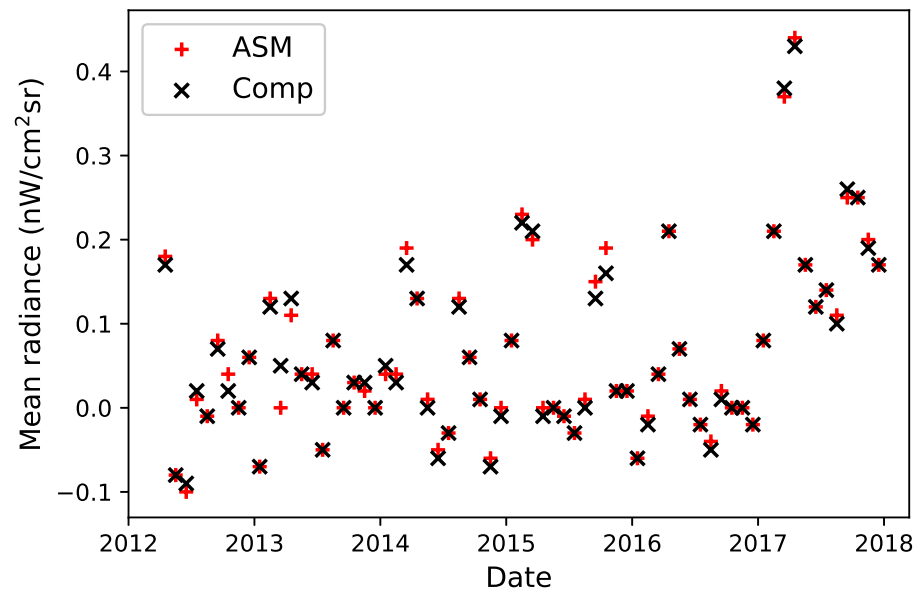

Figure 3. Median radiance for ASM and comparison ("Comp") sites, for each month of the study. ASM sites are shown as a red + and comparison sites as a blue $\mathrm{x}$.
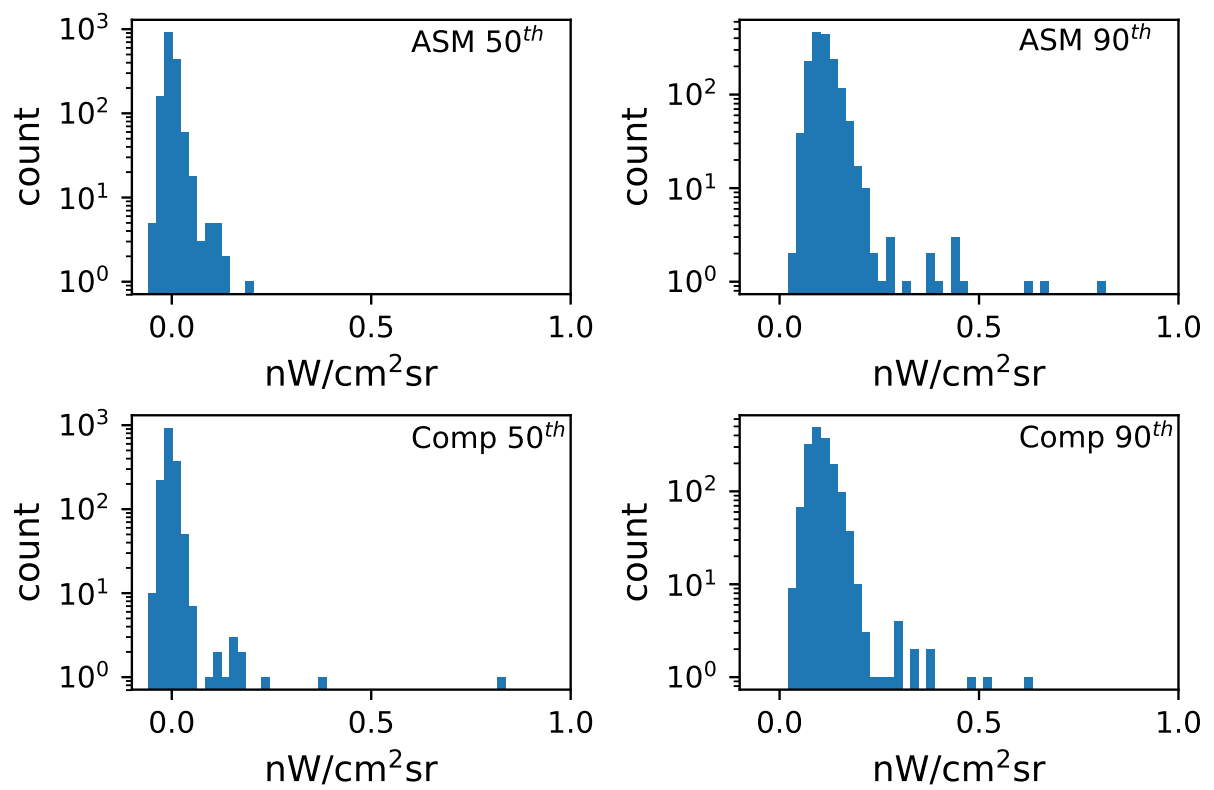

Figure 4. Histogram of radiance values. The top row shows the ASM sites and the bottom the comparison sites. Shown at the left is the median (50th percentile), and at the right is the 90th percentile. A small number of sites (10) are not included in one or more of the plots, as their radiance values are outside of the bounds of the plots.

\section{Conclusions}

The results suggest that space-based observations of nighttime light emissions are not likely to be a useful tool for identifying actively-worked artisanal or illegal mining sites within the Democratic Republic of the Congo, at least at the present level of sensitivity. We cannot rule out the possibility that a sensor with both higher detection sensitivity and higher resolution could detect lights (e.g., flashlights or lamps from armed groups occupying the site, or perhaps even campfires).

It is also possible that lights could be associated only with the beginning of mining (e.g., due to use of fires to clear an area [29]). If this were the case, night lights' products could potentially provide a useful signal of the start of mining activity. If practices in other countries differ from that in the DRC, DNB data could potentially be useful in those contexts. The DNB has an overpass time around 1:30 in the morning, so we also cannot rule out the possibility that a satellite with an earlier overpass time 
might have a chance of observing light emissions during a period when people are more likely to be awake and active.

Unlike industrial mining, artisanal and small-scale mining are mostly informal, and in many cases, even illegal. As a result, ASM may be less likely to have infrastructure permanently on site. Additionally, it is possible that sites migrate over time. These, as well as other factors such as the small-scale nature of the activity or the intense forest cover in the region mean that the detection of ASM can remain challenging. Night lights are, however, clearly associated with active industrial-scale mining both inside and outside of the DRC. While examining industrial open pit mines, we noted that the brightest areas tended to move over time. Night light emissions may therefore provide some information about areas of current or upcoming activity in such sites.

Author Contributions: Conceptualization, C.C.M.K., K.T., and P.L.; funding acquisition, C.C.M.K. and P.L.; investigation, C.C.M.K.; methodology, C.C.M.K. and P.L.; resources, G.G., F.F., and P.L.; visualization, C.C.M.K. and F.F.; writing, original draft, C.C.M.K., G.G., F.F., and P.L.; writing, review and editing, C.C.M.K., G.G., F.F., K.T., and P.L.

Funding: This research was partially funded through the European Union's Horizon 2020 research and innovation program ERA-PLANET, Grant Agreement No. 689443, via the GEOEssential project. C.K. acknowledges funding from the Helmholtz Association Initiative and Networking Fund under Grant ERC-RA-0031.

Acknowledgments: We thank IPIS [16] for making their data public. We also thank Alexandre Jaillon for reviewing a preliminary version of this manuscript prior to submission.

Conflicts of Interest: The authors declare no conflict of interest. The funders had no role in the design of the study; in the collection, analyses, or interpretation of data; in the writing of the manuscript; nor in the decision to publish the results.

\section{Abbreviations}

The following abbreviations are used in this manuscript:

ASM Artisanal and Small-scale Mining

DNB Visible Infrared Imaging Radiometer Suite Day/Night Band

EO Earth Observation

DRC The Democratic Republic of the Congo

IPIS International Peace Information Service

NOAA National Oceanic and Atmospheric Administration

\section{References}

1. Kyba, C.; Garz, S.; Kuechly, H.; de Miguel, A.S.; Zamorano, J.; Fischer, J.; Hölker, F. High-Resolution Imagery of Earth at Night: New Sources, Opportunities and Challenges. Remote Sens. 2015, 7, 1-23. [CrossRef]

2. Geronimo, R.; Franklin, E.; Brainard, R.; Elvidge, C.; Santos, M.; Venegas, R.; Mora, C. Mapping Fishing Activities and Suitable Fishing Grounds Using Nighttime Satellite Images and Maximum Entropy Modelling. Remote Sens. 2018, 10, 1604. [CrossRef]

3. Franklin, M.; Chau, K.; Cushing, L.J.; Johnston, J. Characterizing flaring from unconventional oil and gas operations in south Texas using satellite observations. Environ. Sci. Technol. 2019, 53, 2220-2228. [CrossRef] [PubMed]

4. Liousse, C.; Keita, S.; Granier, L.; Granier, C.; Elvidge, C.D.; Elguindi, N.; Law, K. Flaring emissions in Africa: Distribution, evolution and comparison with current inventories. Atmos. Environ. 2019, 199, 423-434.

5. Elvidge, C.D.; Baugh, K.; Zhizhin, M.; Hsu, F.C.; Ghosh, T. Supporting international efforts for detecting illegal fishing and GAS flaring using VIIRS. In Proceedings of the 2017 IEEE International Geoscience and Remote Sensing Symposium (IGARSS), Fort Worth, TX, USA, 23-28 July 2017; pp. 2802-2805.

6. Oozeki, Y.; Inagake, D.; Saito, T.; Okazaki, M.; Fusejima, I.; Hotai, M.; Watanabe, T.; Sugisaki, H.; Miyahara, M. Reliable estimation of IUU fishing catch amounts in the northwestern Pacific adjacent to the Japanese EEZ: Potential for usage of satellite remote sensing images. Mar. Policy 2018, 88, 64-74. [CrossRef]

7. Duan, H.; Cao, Z.; Shen, M.; Liu, D.; Xiao, Q. Detection of illicit sand mining and the associated environmental effects in China's fourth largest freshwater lake using daytime and nighttime satellite images. Sci. Total Environ. 2019, 647, 606-618. [CrossRef] [PubMed] 
8. United Nations Environment Programme. Post-Conflict Environmental Assessment of the Democratic Republic of Congo: Synthesis Report for Policy Makers. Technical Report. 2011. Available online: http: / /hdl.handle.net/20.500.11822/22069 (accessed on 18 April 2019).

9. Cuvelier, J. The Complexity of Resource Governance in a Context of State Fragility: The Case of Eastern DRC; International Alert: London, UK, 2010.

10. Geenen, S. A dangerous bet: The challenges of formalizing artisanal mining in the Democratic Republic of Congo. Resour. Policy 2012, 37, 322-330. [CrossRef]

11. Maystadt, J.F.; De Luca, G.; Sekeris, P.G.; Ulimwengu, J. Mineral resources and conflicts in DRC: A case of ecological fallacy? Oxf. Econ. Pap. 2014, 66, 721-749. [CrossRef]

12. D'Souza, K. Artisanal Mining in the DRC: Key Issues, Challenges and Opportunities; Communities and Small-Scale Mining, Staffordshire: Kinshasa, Congo, 2007.

13. BSR. Conflict Minerals and the Democratic Republic of Congo: Responsible Action in Supply Chains, Government Engagement and Capacity Building; BSR: San Francisco, CA, USA, 2010.

14. Haufler, V. Disclosure as governance: The extractive industries transparency initiative and resource management in the developing world. Glob. Environ. Politics 2010, 10, 53-73. [CrossRef]

15. Weyns, Y.; Hoex, L.; Matthysen, K. Analysis of the Interactive Map of Artisanal Mining Areas in Eastern DR Congo; IPIS: Antwerp, Belgium, 2016.

16. IPIS. Map DRC v5. Available online: http://www.ipisresearch.be/mapping/webmapping/drcongo/v5/\#3/28/5/2/1 (accessed on 19 October 2018).

17. Stoop, N.; Verpoorten, M.; Van der Windt, P. More legislation, more violence? The impact of Dodd-Frank in the DRC. PLoS ONE 2018, 13, e0201783. [CrossRef] [PubMed]

18. Hinton, J.J.; Veiga, M.M.; Veiga, A.T.C. Clean artisanal gold mining: A utopian approach? J. Clean. Prod. 2003, 11, 99-115. [CrossRef]

19. Telmer, K.H.; Veiga, M.M. World emissions of mercury from artisanal and small scale gold mining. In Mercury Fate and Transport in the Global Atmosphere; Springer: Berlin, Germany, 2009; pp. 131-172.

20. Langford, N.; Ferner, R. Toxicity of mercury. J. Hum. Hypertens. 1999, 13, 651. [CrossRef] [PubMed]

21. National Centers for Environmental Information, National Oceanic and Atmospheric Administration. VIIRS DNB Nighttime Lights Composites. 2012-2017. Available online: https:/ /www.ngdc.noaa.gov/eog/viirs/ download_dnb_composites.html (accessed on 2 May 2018).

22. Miller, S.D.; Straka, W.; Mills, S.P.; Elvidge, C.D.; Lee, T.F.; Solbrig, J.; Walther, A.; Heidinger, A.K.; Weiss, S.C. Illuminating the Capabilities of the Suomi National Polar-Orbiting Partnership (NPP) Visible Infrared Imaging Radiometer Suite (VIIRS) Day/Night Band. Remote Sens. 2013, 5, 6717-6766. [CrossRef]

23. Elvidge, C.D.; Baugh, K.; Zhizhin, M.; Hsu, F.C.; Ghosh, T. VIIRS night-time lights. Int. J. Remote Sens. 2017, 38, 5860-5879. [CrossRef]

24. Miller, S.; Mills, S.; Elvidge, C.; Lindsey, D.; Lee, T.; Hawkins, J. Suomi satellite brings to light a unique frontier of nighttime environmental sensing capabilities. Proc. Natl. Acad. Sci. USA 2012, 109, 15706-15711. [CrossRef] [PubMed]

25. Uprety, S.; Cao, C.; Gu, Y.; Shao, X. Improving the low light radiance calibration of S-NPP VIIRS Day/Night Band in the NOAA operations. In Proceedings of the 2017 IEEE International Geoscience and Remote Sensing Symposium (IGARSS), Fort Worth, TX, USA, 23-28 July 2017; pp. 4726-4729.

26. Stare, J.; Kyba, C. Radiance Light Trends [Web Application]. GFZ Data Serv. 2019.[CrossRef]

27. Coesfeld, J.; Anderson, S.; Baugh, K.; Elvidge, C.; Schernthanner, H.; Kyba, C. Variation of Individual Location Radiance in VIIRS DNB Monthly Composite Images. Remote Sens. 2018, 10, 1964. [CrossRef]

28. Ryan, R.E.; Pagnutti, M.; Burch, K.; Leigh, L.; Ruggles, T.; Cao, C.; Aaron, D.; Blonski, S.; Helder, D. The Terra Vega Active Light Source: A First Step in a New Approach to Perform Nighttime Absolute Radiometric Calibrations and Early Results Calibrating the VIIRS DNB. Remote Sens. 2019, 11, 710. [CrossRef]

29. Elvidge, C.D.; Zhizhin, M.; Baugh, K.; Hsu, F.C.; Ghosh, T. Extending Nighttime Combustion Source Detection Limits with Short Wavelength VIIRS Data. Remote Sens. 2019, 11, 395. [CrossRef]

(C) 2019 by the authors. Licensee MDPI, Basel, Switzerland. This article is an open access article distributed under the terms and conditions of the Creative Commons Attribution (CC BY) license (http://creativecommons.org/licenses/by/4.0/). 